\title{
NATIONAL COMMITTEE ON PHYSICISTS AND MATHEMATICIANS
}

Recent action by the National Headquarters of the Selective Service System recognizes a critical shortage in the field of mathematics and sets up a new procedure whereby a national point of view may be brought to bear on the decisions of local boards in the cases of registrants who are occupied as mathematicians or are students of mathematics. This recent action of National Headquarters is best understood by reference to the historical background.

On November 7, 1942, National Headquarters announced a policy under which the Director of Selective Service might authorize the appointment of a National Committee in a critical scientific or specialized field, to assist the Selective Service System by reviewing affidavits for occupational classification; at the same time the National Committee on Physicists was established. On April 5, 1943, this policy was amended so as to apply to mathematicians as well as to physicists; the National Committee on Physicists was replaced by the National Committee on Physicists and Mathematicians. In addition to the two physicists who, with representatives of the National Roster of Scientific and Specialized Personnel and of the public, constituted the earlier Committee, the new National Committee on Physicists and Mathematicians will include two mathematicians.

This procedure involves no change in the fundamental principles underlying the granting of occupational deferment, which remains, in the first instance, a matter for the decision of each registrant's local board. The creation of the National Committee on Physicists and Mathematicians does, however, provide a means whereby the individual local boards will be advised concerning the national as well as the local needs in the critical fields of both physics and mathematics.

In Memorandum F (see Bulletin of the American Mathematical Society, March, 1943) attention was called to amendments made on December 14, 1942, to Occupational Bulletins No. 10 and No. 23. The amended Bulletins remain in force and should be consulted in preparing requests for occupational classification of teachers or students of mathematics. ${ }^{1}$

Mathematicians should note the changes in procedure made necessary by the establishment of the National Committee on Physicists

${ }^{1}$ The substance of the amended Bulletins No. 10 and No. 23 is to be found also in Activity and Occupation Bulletins No. 33-5 and No. 33-6, issued on March 1, 1943. 
and Mathematicians. The principal one is that the employer is now to file papers with the National Committee as well as with the employee's local board. (See 3(b) below.) The following detailed outline, it is hoped, will be of value to mathematicians and their employers as the new procedure goes into effect.

1. Although full responsibility for presenting occupational deferment requests lies with employers, ${ }^{2}$ the mathematician-registrant will be wise to see that his employer is fully informed of the new procedure established by Activity and Occupation Bulletin No. 35 as amended on April 5, 1943.

2. The employer must first decide whether he regards the registrant as a "necessary" man for whom he wishes to request occupational deferment (or continued occupational deferment). In the case of men with dependents, even if deferred at present, it is desirable to file information with the local boards establishing their occupational status as further ground for deferred classification.

3. For every registrant for whom occupational deferment (or continued deferment) is to be requested, the employer will:

(a) Fill out completely Selective Service Form 42 or $42 \mathrm{~A}$ in triplicate. File a copy with the local board with a brief letter stating that the original has been sent to the National Committee on Physicists and Mathematicians as authorized in Selective Service Activity and Occupation Bulletin No. 35, issued March 1, 1943, and amended April 5, 1943.

(b) Send the original and one copy of Form 42 or $42 \mathrm{~A}$ (see also (c) below) to the:

National Committee on Physicists and Mathematicians

National Roster of Scientific and Specialized Personnel Washington, D. C.

(c) Send in addition to Form 42 or $42 \mathrm{~A}$, a "Report of Status" for the National Committee on Physicists and Mathematicians. Copies of these "Report of Status" blanks may be secured from the National Committee on Physicists and Mathematicians.

(d) For those not now deferred, this procedure should be followed at once. For those now deferred, this procedure should be followed at least thirty days before the expiration of the deferment period.

4. For every registrant for whom deferment is not to be requested

2 Throughout this discussion the term "employer" means that person within an organization-industrial, educational, or governmental-who has been assigned the responsibility for handling deferment problems. In educational institutions, the head of the mathematics department must be an active adviser in matters involving both staff and students. 
by his employer or college, a "Report of Status" in duplicate should be filled out and sent to the National Committee on Physicists and Mathematicians at once so that efforts may be made to place him where his talents and training will be of best service to the war effort.

The plan under which deferment applications for mathematicians are now to be made is announced in Activity and Occupation Bulletin No. 35, as amended on April 5, 1943. Extracts giving the essential features of this plan are published herewith:

"Filing Affidavit-Occupational Classification. When such a National Committee has been appointed for a scientific or specialized field, the employer or recognized university or college desiring occupational classification for a registrant who possesses the training, qualification, or skill in that field, or is in training or preparation therefor, may prepare Affidavit - Occupational Classification (Form 42 or 42A) in duplicate, file the copy with the local board in the usual manner, and forward the original to the National Committee. (Part I, C, 3)

"Action by the National Committee. When the National Committee receives a Form 42 or $42 \mathrm{~A}$, it will investigate the registrant. If, in its opinion, the registrant possesses the training, qualification, or skill and is a necessary man in an essential activity or a necessary man in training or preparation therefor, the National Committee is authorized to place a stamped endorsement prescribed by the Director of Selective Service on the original Form 42 or $42 \mathrm{~A}$ and to file the form with the registrant's local board.

(Part I, C, 4)

"Consideration by local board. When the original Form 42 or $42 \mathrm{~A}$, stamped by the National Committee, is received by the local board, it shall be considered as showing that the registrant has been investigated, that in the opinion of the National Committee he possesses the training, qualification, or skill required, and that, as the case may be, he is a necessary man in an essential activity or a necessary man in training or preparation in such scientific and specialized field.

$$
\text { (Part I, C, 5) }
$$

"Classification Advice (Form 59). When a Form 42 or 42A, stamped by a National Committee, has been received for a registrant and the local board, nevertheless, classifies the registrant as available for military service or for assignment to work of national importance, the local board shall notify the National Committee, as well as the employer or university or college, by mailing to the National Committee and to the employer or university or college Classification Advice (Form 59). In such case the National Committee, as well as the employer or university or college, may appeal to the board of appeal from classification of the registrant.

(Part I, C, 6) 
"National Committees.* The following National Committees for scientific and specialized fields presently are authorized by the Director of Selective Service:

\section{Physicists and Mathematicians}

The National Committee on Physicists and Mathematicians, National Roster of Scientific and Specialized Personnel, Washington, D.C.

\section{Engineers AND Chemists}

The National Committee on Engineers and Chemists, National Roster of Scientific and Specialized Personnel, Washington, D. C." (Part I, C, 7)

May 11, 1943.

J. R. KLINE, Secretary

\footnotetext{
* As amended 4-5-43.
} 